\begin{tabular}{|c|c|}
\hline A & $\begin{array}{c}\text { International Journal of Current Research } \\
\text { and Academic Review }\end{array}$ \\
\hline $\begin{array}{l}\text { EXCELLENT } \\
\text { PUBLISHERS }\end{array}$ & $\begin{array}{c}\text { ISSN: 2347-3215 (Online) Volume } 7 \text { Number } 1 \text { (January-2019) } \\
\text { Journal homepage: http://www.ijcrar.com }\end{array}$ \\
\hline
\end{tabular}

doi: https://doi.org/10.20546/ijcrar.2019.701.001

\title{
Academic Stress and Performance of School Students: A Study of Banepa Muncipality
}

\author{
Pratima Pote* \\ Master in Social Work Programme, Faculties of Humanities and Social Sciences, Tribhuvan University, Nepal \\ *Corresponding author
}

\begin{abstract}
Academic stress is a common psychological issue among school and college students. Stress and anxiety among the students caused by academics is potential to affect their physical and mental health, and their performances. Despite its adverse impacts on the psycho-social well-being and performance of students, academic stress seems to be less attended and few research and study has been carried out on it in Nepal's context. The purpose of this study is to find the prevalence of academic stress and test anxiety level among grade 12 science students, various factors associated with academic stress. The study involves extraction of primary data through questionnaire filling with socio-demographic features, academic stress and test anxiety tools followed by literature review of previous researches and studies on the topic. The rationale behind the study is to bring awareness among the students, guardians, teachers, and key persons in the education system about the factors, situational education system, and social context that are causing academic stress and test anxiety among students. Academic stress and test anxiety level of 173 students $(\mathrm{F}=100, \mathrm{M}=73)$ studying science faculty in grade 12 were measured. Though the study found a high level of academic stress and test anxiety, examining the significance, academic stress was not associated with sibling status, birth order, parental education, performance category of students. Except for test anxiety level which was found to be associated with gender and weak positive correlation between academic stress and test anxiety level was observed.
\end{abstract}

\section{Introduction}

Academic stress is stress pertaining to studies and school activities. Verma and Gupta (1990) has defined academic stress as mental distress with respect to some anticipated frustration associated with academic failure or even unawareness to the possibility of such failure. Academic stress is the feeling of anxiety over one's academic performance which can potentially affect students being unable to perform to the best of their abilities during school and in examinations (Prabu, 2015). Studying, homework, tests, labs, quizzes, extra-curricular activities,

\section{Article Info}

Accepted: 22 December 2018

Available Online: 20 January 2019

\section{Keywords}

Academic Stress, Test Anxiety, Higher Secondary Students, Adolescent mental health. 
the subjects, procrastinate doing the homework, lies to parents, apathetic in school activities, poor performance, withdrawal tendency from socializing among friends, may isolate oneself or even drop out from school.

Higher secondary education is a very important phase in a student's life as their performance and grades of this level have a crucial role in deciding the next higher education, and probably career choice too (Rosa and Preethi, 2012, as cited in Ghatol, 2017). Excessive stress during this stage disturbs them psychologically, confuses them more because they are in pressure to pick the best choice for them. Therefore, excessive stress during this stage could results in increased prevalence of psychological problems like depression and nervousness (Waghacharve et al., 2013, as cited in Ghatol, 2017). The academic class work, relationship with the opposite sex, concern about grades, feelings about personal appearance, pressures to succeed and achieve, testtaking, feelings about self-worth and personal respect, peer acceptance, relationship with friends, and problems at school are major stressors during late adolescence (Peach, 1991, as cited in Ghatol, 2017). The disturbed family dynamics, peer pressure, inability to cope with studies, drug abuse, and lack of competence are major stress triggers for adolescents (Huli, 2014, as cited in Ghatol, 2017).

Academic stress or stress caused by other factors inhibits the performance of the students. Students cannot focus properly during class and on their assigned tasks. However, stress to some extent is good as it makes students to think of and do their assignments and preparations for the examination. But too much of stress causes them to lose concentration and falters their performance. Stress affects the problem-solving ability, creativity, ability to concentrate and instant thinking of students. Continued stress for longer period, definitely affects their grades, including their learning and coping abilities. Excessive level of stress deters their physical well-being like lack of sleep, losing appetite, feeling of weakness, stomach cramps, mild headache which are common complaints of students before or during any test, examination, or presentation and can easily onset mental health issues like anxiety, depression.

Most students when stressed up cannot come up with ideas and tactics to solve the problem. Thus, when students faced with some challenges which might even be easy task, because of stress they can't think rational and find the solutions. Stress weakens the coping mechanism and causes adolescents to be tangled in their problematic thoughts, cannot acknowledge their own interest and strengths. In the lack of proper counseling by their elders, they can be choosing unsuitable field of study for themselves and irrelevant career options from which they cannot bring out the best of themselves, excel and live to the fullest.

Chen (as cited in Ghatol, 2017) discussed that children's social competence and peer acceptance and in turn adjustment are determined by their academic achievement. Pressure of study and performing better among the class mates stresses the students, out of which they cannot enjoy their social life with friends and family. They are always pre-occupied with the thoughts of the study and the future worries. Anger and irritability like emotional experience becomes common among the students. Students might fail to build healthy bonding among the friends and teachers. Some adolescent students might feel that their parents are concerned for the grades of their children, in such situations the likelihood of clashes and bitterness in the parent children relationship is there and might keep themselves emotionally away from their guardians. Often, students do not seek help for a problem or recognize that they have one until it is severely interfering with their overall functioning (Hess, 2014). Distressed experience, left unresolved during adolescence might bring problematic years in adulthood. Marks, Sobanski, and Hine state negative thinking and behavior patterns adapted during adolescence could increase the likelihood of developing psychological maladjustment when dealing with stressful life events (Hess, 2014).

Academic stresses have detrimental impact on students' emotional states during their daily activities and create a variety of somatic symptoms (Verma and Gupta, 1990). The nervous breakdowns, panic attacks, burnouts, reluctance and depression are apparent in many younger students. When distress, anxiety like psychological discomfort is constantly getting in the way for student's overall functioning, they develop psychosocial difficulties and school can be a difficult place for them to be and are at greater risk for depression, addiction, eating disorders, and suicidality (Miller et al., 2011 as cited by Hess, 2014).

Early knowledge of coping and early intervention is important for proper long-term management of anxiety concerns and can decrease future secondary disorders such as depression, suicide, and substance abuse (Muris et al., 2002; Miller et al., 2011; as cited in Hess, 2014). 
Test anxiety is defined as the set of affective, physiological, cognitive and behavioral responses that include emotionality, worry, cognitive interference, and a lack of self-confidence experiencing distress and anxiety, accompanied with concern for possible negative consequences contingent upon performance in any testing or evaluative situation (Zeidner, 1998; Donaldson et al., 2002; Whitaker et al., 2007; as cited in Bagana et al., 2011). Test anxiety is associated with negative stimulation about an evaluation that experiences an inability to think or remember, a feeling of tension, and difficulty in comprehending simple content or directions on an examination (Nicaise, 1975; Suinn, 1968; Ringeisen and Buchwald, 2010, as cited in Bagana et al., 2011). Test anxiety is one of a debilitating, disruptive factor in all academic level from elementary to higher education (Tobias, 1980; Sarason, 1984; as cited in Birenbaum and Naseer, 1994). According to Spielberger and Sarason (as cited in Rani, 2017) excessive level of test anxiety can interfere with cognitive activity, such as memory recall, distractibility, and deficits in general concentration. There is a significant and negative relationship between test anxiety and academic achievement (Gaudry and Spielberg, 1971; Chapell et al., 2005; Khalid and Hasan, 2009; as cited in Rana and Mahmood, 2010). Hembree (1988) have quoted that test anxiety is inversely related to students' self-esteem and directly to their fears of negative evaluation, defensiveness, and other forms of anxiety.

Education system in Nepal is more theoretical and syllabus based than pragmatic. The evaluation system is such that the performances and hard work done in previous assessment are not taken into consideration and only the grade obtained in final examination is valued. Teaching practice is one-way communicative teaching method; hardly any reforms are made in the teaching process and methods. One size fits all education system does not enable all students. The education system is still same developed decades ago. Current education system is putting strain among the students to which the vulnerability of adolescents increases. In addition, comparison among the students and sibling made by the teachers and guardian about their study dreads them, which acts as demotivation. Competitiveness among class mates for ranks and grades can contribute to adjustment difficulties and ruin bonding among the students. Thus, school years are characterized by conditions of extreme pressure where anxiety triggers are frequent or may heighten anxieties already present.
This study aims to highlight how the schooling and parents are adversely influencing the psychological wellbeing of the students and seek to sensitize the concerned stakeholders towards the issue. The study will assist in recognizing and addressing students' mental health concerns using the opportunity of school environment. Removing the barriers, such as academic stress, anxiety and other mental health problems, in school settings improves the performance and overall development of the students. The current study has attempted to explore relationship between academic stress and test anxiety with gender and performance category of the students, correlation between academic stress and test anxiety. The study is an attempt to explore about the causes, factors responsible for the academic stress and test anxiety. The outcome of the study will provide the basis for enhancing or adopting new, positive approach to teaching methods, which will improve the learning and performance of the students in relevance to responsible causes and factors. This will help counselors, school teachers and administration to determine how specific academic stress related interventions can be introduced within the school setting or the reforms required in the teaching methods.

\section{Materials and Methods}

This study followed a quantitative, non-experimental, descriptive design, examining the prevalence of problematic academic stress and test anxiety among higher secondary level students. Total number of participant students was 173 , out of which 100 are females and rest 73 are male students. Only private schools' science faculty grade 12 students of Banepa municipality were assessed for sampling. Students beyond the age of 19 and students with special needs were not included as respondent for the data collection. Students from the government schools were not included in the sampling process.

Data required for the study was collected using questionnaire which included the following:

- Questionnaire for Socio-demographic information

- Educational Stress Scale for Adolescents

- Test Anxiety Inventory

The socio-demographic features included their name, age, sex, religion, ethnicity, father's and mother's education level, family size, sibling status, birth order and their grades in previous and recent examinations. The entire questionnaire package was translated into 
Nepali so that students could properly understand all the statements. To measure the level of academic stress psychological inventory Educational Stress Scale for Adolescents (Sun et al., 2012) was applied. The inventory has sixteen statements encircling five factors as pressure from study, workload, and worry about grades, self-expectations and despondency. The tool has total internal consistency with Cronbach reliability test $\alpha$ 0.81 . The statements are rated using Likert's Five- point Scale from 1 to 5 from strongly agree to strongly disagree. Calculating the scores, the stress level of students is classified into five ranges very low level to very high level.

Test Anxiety Inventory developed by University of Wisconsin, USA measures anxiety caused by taking any test or exams and helps in asserting that stress experienced by the students is caused by their academics. The test anxiety inventory involves statements that indicate the sources and expressions of anxiety. The source of anxiety involves concerns about how others will view if poorly performed, concern rising from threats to own self-image, future security and not being prepared etc. and expressions involves bodily reactions and thought disruptions.

In the test anxiety inventory, the respondents had to mark tick or cross if the students have the similar experience from the statements. For each statement, 1 for each 'yes' or tick mark and 0 for 'no' response or cross mark. The inventory had fifty statements, thus 50 is the maximum score possible and 0 is the minimum score possible. Higher the total score, higher is the level of test anxiety. Summing the scores, the anxiety level of students is classified into five ranges of very low level to very high level. As the scores provided by the students, the students are categorized according to their performance. The performance of the students is categorized as poor, average, good and very good performing students.

\section{Procedure}

Sampling schools were approached with approval letter for study from the Social work department of the University. Every school's administrative staffs were explained about the study and tools that are going to be used and took consent for the same. Before beginning the data collection, a quick overview about the study which included study objectives, procedures, respondent criteria were explained to the students. Participation for the study was made voluntary and anonymous. Students were asked to answer the questionnaires by themselves without discussing with their classmates. It was emphasized to the students that there is no right or wrong responses and expresses their real experiences. They were assured of confidentiality of their responses and their individual results. Instructions on filling the questionnaire set was explained to the students and could ask the researcher if they did not understand any statements or if any kind of confusion. The questionnaire sets were distributed to the students and were instructed about filling the questionnaire set. The researcher was present while participants filled out the tests to clarify if there were any confusion. It took 45 minutes to complete the test. After completion of the test the students were thanked for their kind assistance and cooperation.

\section{Data and findings}

Data are analyzed using the SPSS version 16.0 and the statistical test with two tailed significance level of $\alpha<.05$ is applied. Descriptive analysis was done with frequencies, percentage, and cross tabulation. Expected association between academic stress and study factors were tested using Chi-Square test and Spearman Correlation Coefficient.

\section{Results and Discussions}

\section{Findings}

Prevalence of high level of academic stress and test anxiety is the most frequent. Stress and anxiety level experience is more frequent among females than in males. The results showed test anxiety is significantly related with gender. Prevalence of academic stress is highest among the students with three or more siblings. Youngest born are found to have experienced high academic stress level in comparison to first and middle born.

Students with parents with no academic qualification experienced high level of academic stress was the highest where students with parents with University level education experienced medium level of academic stress. Average performing students are slightly more in experiencing academic stress from the poor and the good performing students but there is no distinctive difference among category of students based on their performance.

The significance results showed that academic stress is not associated with gender, birth order, sibling status, parental education and category of students based on their performance (Table 1-4). 
Table.1 Frequency of academic stress and test anxiety by gender

\begin{tabular}{|l|l|c|c|c|c|}
\hline \multicolumn{2}{|l|}{} & Low (\%) & Medium (\%) & High (\%) & Very High (\%) \\
\hline Academic Stress & Female & & $18(18)$ & $67(67)$ & $15(15)$ \\
\hline & Male & & $19(26)$ & $45(61.6)$ & $9(12.3)$ \\
\hline Test Anxiety & Female & $2(2)$ & $27(27)$ & $53(53)$ & $18(18)$ \\
\hline & Male & $13(17.8)$ & $21(28.8)$ & $37(50.7)$ & $2(2.7)$ \\
\hline
\end{tabular}

Source: Field Data, 2018

Table.2 Academic stress and associated factors

\begin{tabular}{|c|c|c|c|c|}
\hline & \multicolumn{3}{|c|}{ Academic Stress } \\
\hline & & Medium & High & Very High \\
\hline \multirow[t]{3}{*}{ Birth Order } & First & $19(26)$ & $47(64.4)$ & $7(9.6)$ \\
\hline & Middle & $6(14.6)$ & $25(61)$ & $10(24.4)$ \\
\hline & Youngest & $12(20.3)$ & $40(67.8)$ & $7(11.9)$ \\
\hline \multirow[t]{4}{*}{ Sibling Status } & Single & $4(40)$ & $6(60)$ & 0 \\
\hline & One Sibling & $18(24.6)$ & $44(60.3)$ & $11(15.1)$ \\
\hline & Two sibling & $11(17.8)$ & $41(66.1)$ & $10(16.1)$ \\
\hline & $\begin{array}{l}\text { Three or More } \\
\text { sibling }\end{array}$ & $4(14.3)$ & $21(75)$ & $3(10.7)$ \\
\hline \multirow{3}{*}{$\begin{array}{l}\text { Father's } \\
\text { Education }\end{array}$} & No Schooling & 0 & $10(90.9)$ & $1(9.1)$ \\
\hline & High School & $24(20)$ & $79(65.8)$ & $17(14.2)$ \\
\hline & $\begin{array}{l}\text { University } \\
\text { level }\end{array}$ & $13(30.9)$ & $23(54.8)$ & $6(14.3)$ \\
\hline \multirow{3}{*}{$\begin{array}{l}\text { Mother's } \\
\text { Education }\end{array}$} & No Schooling & $6(19.3)$ & $21(67.7)$ & $4(13)$ \\
\hline & High School & $24(18.9)$ & $84(66.1)$ & $19(15)$ \\
\hline & $\begin{array}{l}\text { University } \\
\text { level }\end{array}$ & $7(46.7)$ & $7(46.7)$ & $1(6.6)$ \\
\hline \multirow{4}{*}{$\begin{array}{l}\text { Performance } \\
\text { Category }\end{array}$} & Poor & $5(16.1)$ & $21(67.7)$ & $5(16.1)$ \\
\hline & Average & $8(13.8)$ & $40(69)$ & $10(17.2)$ \\
\hline & Good & $11(22.4)$ & $33(67.3)$ & $5(10.2)$ \\
\hline & Very Good & $13(37.1)$ & $18(51.4)$ & $4(11.4)$ \\
\hline
\end{tabular}

Source: Field Data, 2018

Table.3 Correlation between academic stress and test anxiety

\begin{tabular}{lll}
\hline & Value & Asymp. Std. Error \\
& & \\
\hline Spearman Correlation & .397 & .066 \\
N of Valid Cases & 173 & \\
\hline Source: Field Data, 2018 & &
\end{tabular}


Table.4 Academic stress and level of significance

\begin{tabular}{lc}
\hline Associated Factors & Academic Stress \\
\cline { 2 - 2 } & Level of Significance \\
\hline Gender & 0.433 \\
Birth Order & 0.183 \\
Sibling Status & 0.463 \\
Father's Education & 0.150 \\
Mother's Education & 0.050 \\
Performance Category of Students & 0.205 \\
\hline
\end{tabular}

Source: Field Data, 2018

The conclusion of the study is tit found that the students having high level of academic stress also had high level of test anxiety. With respect to gender, gender differences existed in the experience of stress and anxiety among female and male students.

The response to stress by male and female students differed significantly, with female scoring higher in academic stress (Misra and Castillo, 2004; Gyawali, 2013; as cited in Dhakal, 2013). In contrast, some researchers have found that male experiences higher level of stress than females (Milkie and Thoits, 1993; Hyde and Plant, 1995; as cited in Dhakal, 2013). Exploring gender differences with respect to test anxiety and several researchers found females have higher levels of overall test anxiety than males (Hembree, 1988, Mwamwenda, 1994; Cassady and Johnson, 2002; as cited in Rana and Mahmood, 2010). Kania (2014) found no significant difference in the relationship between gender and stress level experience.

There are different gender roles expected for male and females. Male are expected to be tougher, hiding their pain and emotions, and strong to accept responsibilities whereas females are considered as fragile, delicate and emotionally vulnerable. This psychological conditioning may vary stress dealing pattern with gender. Among the students, male students were reported to be deadline driven, seldom make notes, and often discard internal assessments Dhakal (2013) whereas female may dread skipping the classes and assignments. Gender differences regarding academic stress attributes to gender-role socialization, where only girl's behavioral expression of emotions is considered socially appropriate but not for boys (Gilbert and Scher, 1999, as cited in Dhakal, 2013). Expected gender roles and complying and adhering to them like attributes can be considered factors for significant difference in stress and anxiety with respect to gender.
Factors like sibling status, birth order and parental education can have distinctive influence on experiencing the varied level of academic stress by the adolescent students. Spauta and Paulson (as cited in Joseph, 2009) found from their study that birth order and family size affects the adolescents' academic performance. First or single born are found to be more creative and intelligent than the later born (Spears, 1982; Tenibaije, 2002, as cited in Joseph, 2009). But Joseph (2009) found no significant influence of family size and birth order in the academic performance. Hembree (1988) from his study found that later-born are more prone to higher level of test anxiety.

The above citations have talked about the influence on academic performance but do not claim affecting the stress level. It can only be implied that if family size, sibling status, birth order affects the performance, then those factors may affect the academic stress level experience. The attention and resources are distributed among the siblings rather than centered on one. The younger ones are supervised by their elder siblings along with their parents. Younger ones might fear not living up to their elder sibling's academic achievements, which can fuel up or add the stress level.

Parental educational background influences the academic performance of the children (Kassim et al., 2011) and there is significant correlation between parents' qualification and children academic grades (Shoukat, Ilyas, Azam, Ch, n.d.). Students with educated parents are found to perform and score better than students with parents not educated (Farooq et al., 2011). Students who have parents with no educational background might feel more pressure for excelling in their studies. Those children may not get right supervision for their study. Children of such parents might also feel pity about their parents' education level and guilt for not doing well in their study. Such children might take extra stress about 
their study. In the case of children who have highly educated parents, might feel fear of not living up to their parent's achievement and their expectations. The guiding ways and strictness of such parents might bring academic pressure on their children.

Parental academic qualification, timely supervision done, conducive environment created for study like factors highly contribute for the children's academic performances and may affect their experience of stress level. Adolescents surrounded by unfavorable conditions may have poor study habits and low educational performance. Parents who are educated and qualified expect their children to be achiever. Since their childhood parents are much involved, take deep concern and have encouraging attitude for their children education. They provide motivation, encouragement as well as facilities and modern technology required for studies. Right guidance by such parents, considering the interest and capacity of children can lessen the stress level as well, which could the possible reason for students experiencing medium level of stress found in this study.

Mostly the average performers are found to be experiencing the high level of stress. But there is no distinctive difference between stress level and category of students in terms of frequency. There is almost equal percentage of poor, average, good and very good students experiencing different stress level. Hembree (1988) found that test anxiety level was greater for average students than those with high ability and, with nearly the same proportion, greater for low- than for average ability students.

Moderate level of stress and anxiety regarding academics is beneficial as it makes students to study and prepare for the examinations but when the samestress and anxiety falters the academic performance then it needs to be addressed.

The teaching methods, evaluation system practiced here does not serve all the students. Each student has different learning and study habits. The performances of internal assessment, sincerity, and regularity are not considered for final evaluation. The evaluation system is not systematic, is uncertain and not improvised with time. It can be implied that unsystematic evaluation, one-way communicative teaching method, teachers' and parents' unrealistic expectations and treatment is causing academic stress and test anxiety among the students.

\section{Recommendations}

Over a period, there can be significant changes in the education system. Radical change in education system that values the skill and potentials of students rather than grades and ranks of the students can largely reduce the emotional and mental turmoil among students build up by their study. Likewise, with the easy availability of the mental health treatment services and the awareness on the general public about the mental health and mental disorder, the scenario of mental health can be different. Guardians, teachers, school administration themselves can well identify the cases of the stress, anxiety and other mental discomfort among the students and timely address them.

Introducing successful coping strategies may help students avoid the consequences of excessive level of academic stress.

Students need proper counseling while selecting their courses at intermediate level. Parents may help their children in identifying their interest areas, choosing right career path for their future. While choosing courses taking children's interest and aptitude on regard and not imposing decision by the parents is appropriate.

Appreciation and rewarding the students for their good performance and behavior reinforces them for more efforts in the future tests.

In order to alleviate the stress of adolescents, adopting school-based interventions such as better methods of teaching-learning, incorporating stress management programs in curriculum, understanding adolescent psychology and not over expect from them (Waghachavare et al., 2013; Bartwal and Singh, 2014; Dixit and Singh, 2015, as cited in Ghatol, 2017)

An extra-curricular activity that involves creativity, innovation and refreshment has been proven to reduce stress level. Social programs and games fight academic stress and enhance the physical and mental well-being.

Designing evaluation system that acknowledges the overall performance of the student rather than just the exam papers.

Make learning stimulating, participatory and pleasurable and create conducive environment within the both family and schools. Interactive and creative makes the learning refreshing rather than dull and stressing.

Provision of psycho-social counselor in the schools and colleges help students to discuss on issue which will timely address the stress and anxiety a student is facing.

Frequent interaction between school administration and students on designing and scheduling the courses and 
lectures in the academic year facilitates in the overall learning of the students.

\section{Acknowledgements}

I would like to express my sincere gratitude and thankfulness to my supervisor Dr. Pradeep Acharya for his guidance and feedback throughout the study. I would like to express my great appreciation to my program coordinator Dr. Tika Ram Gautam for his encouragement and support. I would like to acknowledge Mr. YubarajAdhikari for his valuable time and suggestion. I express my deep gratitude to University Grant Commission, Nepal for funding my research. I was awarded with UGC Masters Research Support under Humanities and Social Sciences Research Grant, 207475. I am very thankful to all the principals, coordinators and the respondent students from the schools of Banepa Municipality for their time, acceptance and warmth. I am very grateful to my family members and friends who accompanied me in the completion of my study.

\section{References}

Bagana, E., Raciu, A., and Lupu, L. (2011).Self-esteem, optimism and exams' anxiety among high school students. Procedia - Social and Behavioral Sciences, 30, 1331 - 1338.

Birenbaum, M and Fadia M. Nasse, F.M. (1994).On the Relationship between Test Anxiety and Test Performance. Measurement and Evaluation in Counseling and Development, 27(1).

Dhakal, S. (2013). An Assessment of Academic Stress among Students of Bachelor's Level. Retrieved from https://www.researchgate.net/publication/29879161 3

Essel, G., and Owusu, P, (2017). Causes of students' stress, its effects on their academic success, and stress management by students. Retrieved from https://www.theseus.fi/bitstream/handle/10024/1247 92/Thesis\%20Document.pdf? sequence $=1$

Farooq, M.S., Chaudhry, A. H., Shafiq, M. and Berhanu, G. (2011). Factors affecting students' quality of academic performance: A case of secondary school level. Journal of Quality and Technology Management, $\quad 7(2), \quad$ 1-14.Retrievedfrom http://pu.edu.pk/images/journal/secondary/PDF/4_A qsa\%20 and \%20Maryam_v2_issue1.pdf

Fortune, E. A. (1987). Multiple Roles, Stress and WellBeing among MSW Students. Journal of Social Work Education, 23(3), 81-90. Retrieved from http://www.jstor.org/stable/23042856
Ghatol, S.D. (2017). Academic Stress among Higher Secondary School Students: A Review. International Journal of Advanced Research in Education and Technology (IJARET), 4(1) Retrieved from http://ijaret.com/wpcontent/themes/felicity/issues/vo 14issue1/snehalata.pdf

Hembree, R (1988). Correlates, Causes, Effects, and Treatment of Test Anxiety. Review of Educational Research, 58(1), 47-77. Retrieved from https://doi.org/10.3102/00346543058001047

Hess, J. (2014). Anxiety Prevalence among High School Students. Counselor Education Master's Theses. Retrieved from https://digitalcommons.brockport.edu/cgi/viewconte nt.cgi?referer=https://www.google.com.np/ and httpsredir $=1$ and article $=1164$ and context=edc_theses

Joseph, T.D. (2009). Influence of Family Size and family birth order on academic performance of adolescents in higher institution. Pakistan Journal of Social Sciences, 6(3), 110-114 Retrieved from http://docsdrive.com/pdfs/medwelljournals/pjssci/20 09/110-114.pdf

Kassim,A.,Kehinde, M., and Abisola, L.(2011).Parents' education, occupation and real mother's age as predictors of students' achievement in Mathematics in some selected secondary schools in Ogun State, Nigeria. International Journal of African Studies, 145(4),50-60.

Lal, K. (2014). Academic Stress among Adolescent in Relation to Intelligence and Demographic Factors. American International Journal of Research in Humanities, Arts and Social Sciences, 5(1), 123-129

Kania, S.K. (2014). The Relationship Between Gender Differences and Stress. The Huron University College Journal of Learning and Motivation, 52(1).

Prabu, P.S. (2015). A Study on Academic Stress among Higher Secondary Students. International Journal of Humanities and Social Science Invention, 4(10), 63-68.

Rana, R. A and Mahmood, N. (2010). The Relationship between Test Anxiety and Academic Achievement. Bulletin of Education and Research, 32(2), 63- 74.

Shoukat, A, Ilyas, M, Azam, R, and Ch, A.H. Impact of Parents' Education on Children's Academic Performance. Secondary Education Journal, 2(1), 53-59.

Verma, S., and Gupta, J., (1990).Some aspects of high academic stress and symptoms. Journal of Personality and Clinical Studies, 6, 7-12. 


\section{How to cite this article:}

PratimaPote. 2019. Academic Stress and Performance of School Students: A Study of Banepa Muncipality. Int.J.Curr.Res.Aca.Rev. 7(1), 1-9. doi: https://doi.org/10.20546/ijcrar.2019.701.001 